\title{
Prevalence of HIV and hepatitis C markers among a cadaver population in Milan
}

\author{
C Cattaneo, P A Nuttall, L O Molendini, M Pellegrinelli, M Grandi, R J Sokol
}

\begin{abstract}
Aims-To examine the distribution of serological markers for HIV and hepatitis $C$ virus (HCV) infection in a medicolegal population; to compare prevalence of HIV and HCV markers and cause of death; and to evaluate the risk of potential infection to personnel involved in medicolegal incidents and procedures.

Methods-Blood samples were collected at necropsy from 328 males and 69 females, aged 16 to 50 years at time of death, and tested for antibodies to HIV and HCV. The individuals were classified according to cause of death and whether there was known antemortem risk of infection.

Results-Overall, 134 subjects gave positive test results: 20 for anti-HIV, 69 for anti-HCV, and 45 for both. By cause of death, the total number of positives (and negatives) with the pairs of figures referring, respectively, to patients with and without known antemortem risks were: natural causes 3 (1), 8 (32); AIDS 2 (0), 0 (0); homicide 0 (2), 5 (24); suicide $3(0), 9$ (69); road traffic accidents 1 (0), 9 (81); other accidents 2 (3),1 (12); drug overdose 74 (17), 7 (9); unknown causes 3 (2), 7 (11). Conclusions-The cases tested represented a predominantly young male population with a high prevalence of serological markers for HIV and HCV infection. The distribution of HIV and HCV positivity varied with the cause of death, probably reflecting the known association between high risk behaviour and infection. However, a substantial number of cases with no known risks also had markers for HIV and HCV, suggesting that there is a large unrecognised pool of potential infection in medicolegal practice.

(F Clin Pathol 1999;52:267-270)
\end{abstract}

Institute of Legal Medicine, 20133 Milan,

Italy

C Cattaneo

L O Molendini

$M$ Pellegrinelli

M Grandi

National Blood

Service, Trent Centre,

Sheffield S5 7JN, UK

P A Nuttall

R J Sokol

Correspondence to:

Dr Sokol.

Accepted for publication

4 January 1999 ter anonymously all patients with full blown AIDS but not HIV positive individuals without AIDS or those with $\mathrm{HCV}$ infection. In the United Kingdom, both HIV and HCV infections are non-notifiable, although various cooperative reporting systems exist for their surveillance. Doubt must therefore remain as to whether there is a large unrecognised pool of infected individuals in the general population. Resolution of this point might be partly achieved by examining medicolegal necropsies for, although they are a preselected group, it has been suggested that they act as a surrogate for the general population and may be particularly sensitive to early changes in epidemiology. ${ }^{6}$

The present study was performed over a 13 month period on a series of cadavers submitted for necropsy at the Medico-Legal Institute in Milan; cases were referred to the institute either because crime was suspected or the doctor was unable to certify the cause of death. The investigation had three main objectives: first, to examine the distribution of serological markers for HIV and HCV infection in a medicolegal population which included all causes of death; second, to compare prevalence of HIV and HCV markers and cause of death; and third, to evaluate the risk of potential infection to personnel involved in medicolegal incidents and procedures.

\section{Methods}

The study was carried out from 10 December 1996 to 31 December 1997. Samples of blood were collected from 397 bodies at necropsy, carried out within 1 to 38 days of death; 328 were male and 69 female. The individuals were selected only according to age (from 16 to 50 years) and were classified by cause of death: natural causes, AIDS, homicide, suicide, road traffic accidents, other accidents, drug overdose, and unknown causes; classification was irrespective of previous lifestyle. Case records and relatives were consulted as fully as possible to determine whether there was antemortem knowledge of actual or potential risk of infection. Although the completeness of the records varied, by Italian law two relatives had to be interviewed in the presence of a Magistrate's representative. Commercially available microbiology kits were used to test cadaveric serum for HIV and HCV antibodies. HIV testing was performed both by an agglutination screening method and by enzyme linked immunosorbent assay (ELISA); testing for $\mathrm{HCV}$ employed an ELISA system. 
Table 1 Results of HIV and hepatitis C virus (HCV) testing by ELISA on 397 cadavers by cause of death

\begin{tabular}{|c|c|c|c|c|c|c|c|c|}
\hline \multirow{3}{*}{$\begin{array}{l}\text { Cause of death } \\
\text { (number of subjects in } \\
\text { "Known risk" and "No } \\
\text { known risk" groups, } \\
\text { respectively) }\end{array}$} & \multicolumn{8}{|c|}{ Number of positive and negative results } \\
\hline & \multicolumn{4}{|c|}{ "Known risk" group (113) } & \multicolumn{4}{|c|}{ "No known risk" group (284) } \\
\hline & $H I V$ & $\mathrm{HCV}$ & $\begin{array}{l}H I V \text { and } \\
H C V\end{array}$ & $\mathrm{Neg}$ & $H I V$ & $\mathrm{HCV}$ & $\begin{array}{l}H I V \text { and } \\
H C V\end{array}$ & $\mathrm{Neg}$ \\
\hline $\begin{array}{l}\text { Natural causes } \\
(4 ; 40)\end{array}$ & 0 & 1 & 2 & 1 & 2 & 4 & 2 & 32 \\
\hline $\begin{array}{l}\text { AIDS } \\
(2 ; 0)\end{array}$ & 0 & 0 & 2 & 0 & 0 & 0 & 0 & 0 \\
\hline $\begin{array}{l}\text { Homicide } \\
(2 ; 29)\end{array}$ & 0 & 0 & 0 & 2 & 4 & 1 & 0 & 24 \\
\hline $\begin{array}{l}\text { Suicide } \\
(3 ; 78)\end{array}$ & 1 & 1 & 1 & 0 & 5 & 3 & 1 & 69 \\
\hline $\begin{array}{l}\text { Road traffic accidents } \\
(1 ; 90)\end{array}$ & 0 & 0 & 1 & 0 & 2 & 5 & 2 & 81 \\
\hline $\begin{array}{l}\text { Other accidents } \\
(15 ; 13)\end{array}$ & 0 & 1 & 1 & 3 & 1 & 0 & 0 & 12 \\
\hline $\begin{array}{l}\text { Drug overdose } \\
(91 ; 16)\end{array}$ & 1 & 45 & 28 & 17 & 1 & 3 & 3 & 9 \\
\hline $\begin{array}{l}\text { Unknown causes } \\
(5 ; 18)\end{array}$ & 0 & 1 & 2 & 2 & 3 & 4 & 0 & 11 \\
\hline Total $(113 ; 284)$ & 2 & 49 & 37 & 25 & 18 & 20 & 8 & 238 \\
\hline
\end{tabular}

Table 2 Results of HIV and hepatitis C virus (HCV) testing by ELISA on 397 cadavers by age

\begin{tabular}{|c|c|c|c|c|c|c|c|c|}
\hline \multirow{3}{*}{$\begin{array}{l}\text { Age in years (total } \\
\text { number of subjects } \\
\text { in group) }\end{array}$} & \multicolumn{8}{|c|}{ Number of positive and negative results } \\
\hline & \multicolumn{4}{|c|}{ "Known risk" group (113) } & \multicolumn{4}{|c|}{ "No known risk" group (284) } \\
\hline & $H I V$ & $H C V$ & $\begin{array}{l}\text { HIV and } \\
H C V\end{array}$ & $\mathrm{Neg}$ & $H I V$ & $H C V$ & $\begin{array}{l}H I V \text { and } \\
H C V\end{array}$ & $\mathrm{Neg}$ \\
\hline 16 to $20(27)$ & 0 & 1 & 0 & 1 & 1 & 2 & 0 & 22 \\
\hline 21 to $30(147)$ & 0 & 33 & 6 & 14 & 2 & 7 & 1 & 84 \\
\hline 31 to $40(124)$ & 1 & 10 & 26 & 7 & 6 & 3 & 1 & 70 \\
\hline 41 to $50(86)$ & 1 & 4 & 5 & 3 & 6 & 6 & 4 & 57 \\
\hline Unknown (13) & 0 & 1 & 0 & 0 & 3 & 2 & 2 & 5 \\
\hline Total (397) & 2 & 49 & 37 & 25 & 18 & 20 & 8 & 238 \\
\hline
\end{tabular}

Table 3 Results of HIV and hepatitis C virus (HCV) testing by ELISA on 397 cadavers by sex

\begin{tabular}{|c|c|c|c|c|c|c|c|c|}
\hline \multirow{3}{*}{$\begin{array}{l}\text { Cause of death } \\
\text { (total number of } \\
\text { subjects in group) }\end{array}$} & \multicolumn{8}{|c|}{ Number of positive and negative results } \\
\hline & \multicolumn{4}{|c|}{ "Known risk" group (113) } & \multicolumn{4}{|c|}{ "No known risk" group (284) } \\
\hline & $H I V$ & $H C V$ & $\begin{array}{l}H I V \text { and } \\
H C V\end{array}$ & $\mathrm{Neg}$ & $H I V$ & $H C V$ & $\begin{array}{l}\text { HIV and } \\
\mathrm{HCV}\end{array}$ & $\mathrm{Neg}$ \\
\hline Male (328) & 2 & 46 & 34 & 24 & 14 & 18 & 8 & 182 \\
\hline Female (69) & 0 & 3 & 3 & 1 & 4 & 2 & 0 & 56 \\
\hline Total (397) & 2 & 49 & 37 & 25 & 18 & 20 & 8 & 238 \\
\hline
\end{tabular}

HIV TESTING BY AGGLUTINATION

These tests were carried out at the Institute of Legal Medicine, Milan, using the Serodia HIV-1 kit (Fujirebio, Tokyo, Japan). A $25 \mu \mathrm{l}$ sample of serum, diluted 1 in 10 , was incubated in styrene wells with $25 \mu \mathrm{l}$ of HIV antigen sensitised and unsensitised gel particles. The results were read after two hours, a positive being represented by particle agglutination, a negative by lack of agglutination. Control sera (positive and negative) were included in each test run

HIV 1 AND 2 TESTING BY ELISA

Testing was carried out at the Trent Centre, Sheffield, employing the Wellcozyme HIV-1 and HIV-2 (VK 84/5) kit developed by Murex
(Dartford, England). Test and control sera were incubated in the wells of styrene plates containing immobilised HIV-1 and HIV-2 antigens so that any antibodies to HIV-1 or HIV-2 in the sample were bound to the immobilised antigens. Conjugate (HIV antigens labelled with alkaline phosphatase) and primary substrate (NADP) were added sequentially (incubating and washing between steps), followed by enzyme amplification of the colour development stage. The reaction was terminated with sulphuric acid and the colour read with a spectrophotometer at $492 \mathrm{~nm}$. A result was considered positive for anti-HIV if the optical density value of the test equalled or exceeded that of the mean negative control plus 0.20 units.

HCV TESTING

The HCV 3.0 ELISA system (Ortho, Neckargemünd, Germany) was used, testing being carried out at the Trent Centre, Sheffield. Test and control sera were incubated in the wells of styrene plates coated with a mixture of recombinant HCV antigens (C22-3, C200, and NS5) and washed. Murine monoclonal antihuman IgG antibody conjugated to horseradish peroxidase was added, followed by the substrate (O-phenylediamine with hydrogen peroxide). Finally, sulphuric acid was used to stop the reaction and the results read photometrically at $490 \mathrm{~nm}$. A result was considered positive for anti-HCV when the test optical density value equalled or exceeded that of the mean negative control plus 0.30 units.

\section{Results}

The 397 subjects were divided into "known risk" and "no known risk" groups according to whether there was a history of infection, drug addiction, or prostitution (male or female). There were 113 cases with a known risk of infection and 284 with no known risk; the results of HIV and HCV testing by ELISA for these groups are presented by cause of death, age, and sex in tables 1 to 3, respectively. The suicides were all traumatic and resulted from jumping from high buildings or being run over by a metro/train, except for two individuals who drowned themselves. Heroin was the cause of all deaths in the drug overdose group.

Overall, 134 subjects (34\%) gave positive results: 20 for anti-HIV, 69 for anti-HCV, and 45 for both anti-HIV and anti-HCV. The HIV agglutination test gave the same results as ELISA in 395 of the 397 cases; in two known drug addicts with a positive ELISA, who died of heroin overdose, the agglutination results were equivocal $(+/-)$.

\section{Discussion}

The subjects were selected only according to age (from 16 to 50 years) and although all causes of death, from violent to natural, were included, it is difficult to extrapolate conclusions concerning the prevalence of HIV and $\mathrm{HCV}$ onto the general population, as deaths from homicide, suicide, accidents, and drug overdose were overrepresented in the cadaver group. Also, males outnumbered females by 
328 to 69 (table 3), most subjects were in the 21 to 40 year age range (table 2), and most importantly $28 \%$ (113 of the 397 cases) had a history of known risk (table 1). The study does, however, provide important epidemiological information on a young adult population in Milan and has revealed differences from data obtained for living people. The high positivity rate in the drug overdose cases (table 1), where 81 of 107 individuals had markers of infection, can be contrasted with previously untested volunteer blood donors where individuals in risk groups are precluded and the incidence of confirmed HIV and HCV positivity was 1 and 3 per 4500, respectively (Milan Blood Transfusion Centre figures for 1998). It is therefore important to think of society as a series of subpopulations with widely differing prevalences of disease rather than projecting the pattern of $\mathrm{HIV}$ and $\mathrm{HCV}$ infection in specific, selected groups onto the general population.

We have previously demonstrated the applicability and reliability of the techniques used to study cadaveric blood in simulated forensic situations, using samples from individuals who had tested positive or negative in life; no artefactual false positives were seen. ${ }^{7-9}$ It is of particular note that the agglutination and ELISA tests for HIV gave comparable results in 395 cases, the two with an equivocal agglutination reaction being ELISA positive. Either technique would, therefore, be suitable for investigating forensic material and the more robust, less technically demanding agglutination test may be the more useful in a medicolegal setting. Although no confirmatory assays were used for samples found to be anti-HCV positive, the results were repeatable within the same system. A second ELISA could be of value in this respect, but more complex and time consuming methodologies may be needed for definitive confirmation. However, the latter would not be suitable as a screening test aimed at providing rapid results in a forensic situation.

Unlike the present investigation which examined a wide range of subjects for the prevalence of both HIV and HCV infection, the majority of previous studies on cadaveric populations have involved HIV only, usually in at risk populations. ${ }^{6}{ }^{10-17}$ They showed that the rate of HIV positivity in drug addicts varied over periods of time $\mathrm{e}^{13} 16$ and, quite significantly, with geography. ${ }^{15}$ Although, our findings give rise to reservations about extrapolating data, it has been suggested that medicolegal studies involving a wide variety of deaths give useful information on HIV infection, even in low prevalence areas, and may reflect the incidence in the population, being particularly sensitive to early epidemiological changes. ${ }^{6}$ There seems to have been no comparable investigations for $\mathrm{HCV}$ infection.

Medicolegal studies overcome many of the ethical problems usually associated with screening for HIV and HCV infection, but give rise to other difficulties. For example, should the results be divulged to relatives or to other people who might have been at risk, or should they be made public at inquest? There are no clear answers to these problems, which should be dealt with on an individual case basis, though anonymous recording of data would provide valuable information on the prevalence and distribution of HIV and HCV infection in particular sections of a community.

The prevalence of HIV and HCV positivity clearly varies with cause of death (table 1), the drug overdose group having far more positive results (81 of 107 , or $76 \%$ of cases) than other categories, for example traffic and other accidents, where only 13 of 109 cases (13\%) were positive. This is not unexpected and presumably reflects the known association between high risk behaviour (for example, drug addiction or prostitution) and both HIV and $\mathrm{HCV}$ infection ${ }^{3}{ }^{17}$; people in groups with a high risk of infection are far more likely to die at a younger age and in circumstances which require a medicolegal inquiry. Lifestyle and associated risk behaviour would also account for the high number of individuals testing positive for both HIV and HCV, particularly in circumstances where needle sharing is common. Appropriate and complete information was not always available and may have led to misclassification in a limited number of cases. Of particular concern were deaths caused by drug overdose (table 1); there was some doubt as to whether records were complete or relatives honest about clinical histories. However, the important point is that risk behaviour was not known to others antemortem, and therefore the lack of a known history of such a risk factor does not equate with absence of the risk factor. In the case of suicide (table 1), the presence of several HIV positive individuals with no known risk reinforces the view that screening victims for markers of infectious disease is important. ${ }^{6}$

A major finding from this work (table 1) is that a substantial number of people with serological markers for HIV and HCV infection who died of natural causes, accidents, suicide, or homicide had no known clinical or personal history which would indicate contact with the viruses. It must, therefore, be concluded that the known instances of potential infection in medicolegal practice are supplemented by a further substantial number of cases where the risks are unrecognised or unknown and the need to take appropriate precautionary measures, even when dealing with individuals with an apparently low risk medical history, must be stressed. Large numbers of personnel can be put at risk; for instance, 10 individuals were exposed to blood from a road accident casualty who was antibody positive for $\mathrm{HCV}^{18}$ and a male in his 60s acquired HIV infection from removing heavily bloodied bodies from a railway track. ${ }^{19}$ Information may not be forthcoming initially: in one study of 53 cadavers, the positive HIV status was available to the pathologist at necropsy in only 27 cases, although it was known in 48 of them. ${ }^{16}$ In the present investigation, 22 individuals were known to be positive for HIV pre-necropsy, 28 for hepatitis, and seven for both, but in some cases it was not clear whether it was hepatitis C or B. 
We thank Mrs C A Mitchell for secretarial assistance.

1 Metters J, chairman. Unlinked anonymous HIV prevalence monitoring programme England and Wales. Report from the unlinked anonymous surveys steering group. London: the unlinked anonymous sur

2 Dianzani F, Ippolito G, Morano M. AIDS 1998: il contributo Italiano. Padova: PICCIN, 1998.

Italiano. Padova: PICCIN, 1998.
Di Bisceglie AM. Hepatitis C. Lancet 1998;351:351-5.

3 Didberg D, Cameron S, McMenamin J. Hepatitis C virus antibody prevalence among injecting drug users in antibody prevalence among injecting drug users in Health 1998;1:95-7.

5 Ramsay ME, Balogun MA, Collins M, et al. Laboratory surveillance of hepatitis $C$ virus infection in England and Wales: 1992 to 1996. Commun Dis Public Health 1998;1:8994.

6 Karhunen PJ, Brummer-Korvenkontio H, Laaksonen H, et al. Surveillance of human immunodeficiency virus (HIV) antibodies in medicolegal autopsy in Finland-monitoring of early changes in HIV-seropositivity among risk groups and average population. $\mathcal{F}$ Forensic Sci 1992;37:1261-8.

7 Cattaneo C, Nuttall P, Molendini I, et al. HIV testing of cadaveric blood using screening techniques devised for cadaveric blood using screening techniques devised
transfusion practice. Transfus Med 1996;6(suppl 2):37.

8 Cattaneo C, Nuttall P, Sokol RJ. Detection of HIV, hepatitis $\mathrm{B}$ and hepatitis $\mathrm{C}$ markers in discarded syringes and bloodstains. Sci fustice 1996;36:271-4.

9 Cattaneo C, Molendini LO, Nuttall PA, et al. HIV, HCV and HBsAg testing of cadavers: the use of blood transfusion techniques in forensic practice. Transfus Med 1997;7(suppl 1):45
10 Lockemann U, Schulz-Schaeffer W, Wischhusen F, et al. HIV-1 prevalence in fatalities from Hamburg, Germany. Int HIV-1 prevalence in fatalities
f Legal Med 1993;106:11-13.

11 Lockemann U, Püschel K. HIV-1 prevalence among drug deaths - a multi-center study. Forensic Sci Int 1993;62:8993.

12 Kringsholm B, Theilade P, Geertinger P. The occurrence of HIV antibodies in drug addicts autopsied at the University Institute of Forensic Medicine in Copenhagen in 1987. Forensic Sci Int 1989;41:281-4.

13 Kringsholm B, Theilade P. Prevalence of HIV-1 antibodies in drug addicts autopsied at the University Institute of Forensic Pathology in Copenhagen 1988-1991. Forensic Sci Int 1992;55:83-92.

14 Paterson SC, Vanezis P, Claydon SM. Drug addict deaths in North and West London and prevalence of HIV and hepatitis B infection. Sci fustice 1996;36:85-8.

15 Püschel K, Lockemann U, Schneider V, et al. HIV-1prevalence among drug deaths in major cities of central and northern Europe. Forensic Sci Int 1992;57:57-62.

16 Rajs J, Karlsson T, Eklund B, et al. HIV-related deaths outide medical institutions in Stockholm. Forensic Sci Int $1989 ; 41: 269-80$

17 Sadler DW, Pounder DJ, Urquhart GED, et al. Prevalence of IIV antibody in forensic cases. BMF 1992;304:1027-8.

18 Wreghitt TG, Irish N. Transmission of blood-borne viruses after motor-car accidents. Lancet 1998;351:450-1.

19 Gilbart VL, Raeside F, Evans BG, et al. Unusual HIV transmissions through blood contact: analysis of cases reported in the United Kingdom to December 1997. Commun Dis Public Health 1998;1:108-13. 